\title{
HUBUNGAN KUALITAS WEB KANDAGA TERHADAP KEBUTUHAN INFORMASI PENGGUNA
}

\author{
Vina Rufaidah \\ Program Studi Ilmu Perpustakaan Fakultas Ilmu Komunikasi Universitas Padjadjaran \\ Email: vinarufaidah21@gmail.com \\ Wina Erwina \\ Program Studi Ilmu Perpustakaan Fakultas Ilmu Komunikasi Universitas Padjadjaran \\ Email: Erwina.unpad@gmail.com

\section{Andri Yanto} \\ Program Studi Ilmu Perpustakaan Fakultas Ilmu Komunikasi Universitas Padjadjaran \\ Email: andri.yanto@unpad.ac.id
}

\begin{abstract}
Abstrak
Penelitian ini bertujuan untuk mengetahui sejauh mana hubungan kualitas web Kandaga sebagai mesin pencari perpustakaanterhadap kebutuhan informasi pengguna, khususnya mahasiswa di Universitas Padjadjaran. Pengukuran kualitas web menggunakan model WebQual 4.0 dari Barnes dan Vidgen yang terdiri dari Usability, Information Quality, dan Service Interaction. Sedangkan untuk pengukuran kualitas kebutuhan informasi menggunakan teori kebutuhan informasi menurut Guha yang terdiri dari kebutuhan informasi mutakhir, rutin, mendalam, dan sekilas. Metode yang digunakan adalah metode kuantitatif dengan uji korelasional Pearson Product Moment yang bertujuan untuk menguji hubungan sebab akibat antara variabel $\mathrm{X}$ dan $\mathrm{Y}$. Teknik pengumpulan data dalam penelitian ini dilakukan melalui kuesioner, wawancara, dan studi literatur. Populasi pada penelitian ini sebanyak 32.900 mahasiswa dengan responden berjumlah 100 mahasiswa yang ditentukan menggunakan teknik sampel acak sederhana (simple random sampling). Hasil penelitian ini menunjukkan bahwa kualitas web Kandaga terhadap kebutuhan informasi mutakhir, rutin, mendalam, dan sekilas memiliki hubungan yang kuat.
\end{abstract}

Kata kunci: WebQual, mesin pencari perpustakaan,kebutuhan informasi, Kandaga, Universitas Padjadjaran

\begin{abstract}
This research is intended to know Kandaga web quality relation as a library searching engine towards user information needed, especially students of Padjadjaran University. Web quality measurement use WebQual 4.0 model by Barnes and Vidgen that consist of Usability, Information Quality and Service Interaction. Meanwhile in order to measure quality information needed uses the theory of needed information by Guha which consist of current need approach, everyday need approach, exhaustive need approach, and catching up need approach. The method is used is Quantitative Method with correlational treatment Pearson Product Moment which is intended to treat causality between X and Y variables. The collecting data technique in this research is done by questioner, interview and literature study. The population in the research is 32.900 students with 100 students responding which is determined by using simple random sampling. The result of research indicates Kandaga web quality towards the needed latest, daily, going deep and a glance information has strong correlation.
\end{abstract}

Keywords: WebQual, library searching engine, needed information, Kandaga, University Padjadjaran.

\section{PENDAHULUAN}

Kebutuhan informasi merupakan suatu keadaan dimana adanya perbedaan antara pengetahuan yang dimiliki dengan pengetahuan yang di butuhkan. Sehingga dalam memenuhi kebutuhan 
informasinya seseorang akan berupaya mencari atau mendatangi sumber-sumber informasi, seperti perpustakaan, pusat

data informasi, museum, dan lain-lain. Perpustakaan merupakan salah satu tempat penyedia informasi yang diharapkan dapat membantu memenuhi kebutuhan informasi pemustaka.Hal ini tak dapat dipungkiri bahwa keberadaan informasi menjadi sesuatu yang sangat dibutuhkan dan dapat mempengaruhi perilaku individu itu sendiri.

Saat ini perkembangan teknologi informasi dirasakan sangat cepat dan sudah mempengaruhi berbagai bidang kehidupan dan profesi yang menyebabkan perubahan sistem pada berbagai instansi, termasuk instansi pendidikan. Teknologi informasi membuka kesempatan bagi setiap individu untuk mengakses informasi secara luas, yang mana membutuhkan media sebagai wadah untuk mengakses informasi. Salah satu bagian dari teknologi informasi adalah adanya internet yang terhubung dengan jaringan telekomunikasi dan dapat diakses dimanapun dan kapanpun.Saat ini, kebutuhan internet semakin meningkat mengingat peran internet sangat penting dalam kehidupan sehari-hari. Melihat perkembangan tersebut, internet sebagai bagian dari teknologi informasi mengubah bentuk masyarakat lokal menjadi masyarakat global, serta memunculkan sebuah dunia transparan akan perkembangan informasi.

Berdasarkan UU No. 43 Tahun 2007 tentang Perpustakaan menyatakan bahwa, Perpustakaan Perguruan Tinggi adalah perpustakaan yang merupakan bagian integral dari kegiatan pendidikan, penelitian, dan pengabdian kepada masyarakat dan berfungsi sebagai pusat sumber belajar untuk mendukung tercapainya tujuan pendidikan yang berkedudukan di perguruan tinggi.Menurut Erwina \& Yanto (2017), aktivitas layanan perpustakaan perguruan tinggi salah satunya adalah bagaimana perpustakaan memfasilitasi komunikasi ilmiah antar sivitas akademika ataupun masyarakat yang lebih luas terkait dengan hasil penelitian yang dipublikasikan. Saat ini perpustakaan perguruan tinggi dihadapkan pada sebuah tantangan dalam memberikan akses informasi kepada pengguna. Suprianto \& Muhsin (2008) mengatakan bahwa kebutuhan informasi dan perkembangan teknologi informasi sangat berhubungan dengan peran perpustakaan sebagai tempat dalam penyebaran dan pelestarian informasi, rujukan bagi para pencari ilmu, dan pengembangan karya ilmiah.

Mesin pencari informasi atau search engine merupakan suatu sistem berbasis web yang dirancang untuk membantu dan mempermudah pengguna dalam menemukan informasi yang dibutuhkan. . Menurut Riyadi (2009), "mesin pencari merupakan salah satu dari perkembangan teknologi informasi yang dirancang khusus untuk membantu individu dalam mencari informasi baik itu dalam sebuah web ataupun di komputer itu sendiri”. Mesin pencari informasi merupakan inovasi yang hadir di tengah perkembangan teknologi informasi yang dapat di manfaatkan salah satunya oleh perpustakaan perguruan tinggi sebagai penyedia layanan untuk kebutuhan informasi ilmiah.

Suatu perpustakaan menurut Mubasyroh (2016) dalam Yanto \& Erwina (2018), dikatakan baik apabila dapat menyediakan informasi sesuai dengan kebutuhan pemustaka melalui sistem temu kembali informasi yang terorganisir dengan baik. Berdasarkan SNP 010:2011 perpustakaan perguruan 
tinggi dalam kegiatan layanan dan organisasi informasi memanfaatkan teknologi informasi dan komunikasi untuk meningkatkan kinerja perpustakaan dan keperluan pemustaka. Maka dari itu Universitas Padjadjaran (Unpad) meluncurkan sebuah mesin pencari perpustakaan yang dinamakan Web Kandaga

Web Kandaga merupakan sebuah mesin pencari informasiilmiah yang diambil dari bahasa sunda yang berarti tempat untuk menyimpan sesuatu yang sangat berharga. Kandaga merupakan laman pencarian informasi untuk mengakses seluruh konten yang dihasilkan oleh sivitas akademika, seperti Otonomi Perpustakaan, Repositori Digital, Jurnal Unpad, E-Resources, E-Books, dan ELearning. Konsep Kandaga mengambil manifestasi dari tradisional sunda yang dikombinasikan dengan konsep modern untuk membuat sebuah tempat penyimpanan informasi ilmiah. Project ini diinisiasi pada tahun 2016 oleh kepala UPT Perpustakaan Unpad, Dra. Wina Erwina, M.A. dengan melibatkan tim pengembangan perpustakaan digital dari Program Studi Ilmu Perpustakaan Unpad, yaitu Andri Yanto, S.Sos, M.Ikom dan Asep Saeful Rohman S.Sos., M.Ikom, ahli filologi Sunda yaitu Mamat Ruhimat S.S. M.hum serta melibatkan konsultan pengembang Indonsesia OneSearch yang bernama Ismail Fahmi.

Sebagai mesin pencari informasi dikalangan sivitas akademika Unpad, Web Kandaga diharapkan dapat menjadi mesin pencari informasi yang dapat memudahkan pengguna untuk memenuhi kebutuhan informasi.Selain itu, diharapkan dengan adanya Kandaga ini, berbagai koleksi elektronik dapat disimpan dalam satu tempat yang dapat diakses melalui jaringan internet.Pada penelitian ini, peneliti lebih menitik beratkan pada kualitas Kandaga sebagai mesin pencari informasi untuk memenuhi kebutuhan informasi di kalangan mahasiswa aktif Unpad.

Berdasarkan uraian di atas, tujuan dari penelitian ini adalah sebagai berikut: 1) Untuk mengetahui hubungan kualitas web Kandaga terhadap kebutuhan informasi pengguna di Universitas Padjadjaran; 2) Untuk mengetahui hubungan kualitas web Kandaga terhadap kebutuhan informasi mutakhir bagi pengguna di Universitas Padjadjaran; 3) Untuk mengetahui hubungan kualitas web Kandaga terhadap kebutuhan informasi rutin bagi pengguna di Universitas Padjadjaran; 4) Untuk mengetahui hubungan kualitas web Kandaga terhadap kebutuhan informasi mendalam bagi pengguna di Universitas Padjadjaran; 5) Untuk mengetahui hubungan kualitas web Kandaga terhadap kebutuhan informasi sekilas bagi pengguna di Universitas Padjadjaran.

\section{METODE}

Metode penelitian ini menggunakan jenis penelitiankuantitatif. Menurut Sugiyono (2012), "kuantitatif merupakan metode penelitian yang berlandaskan pada filsafat positivism, digunakan untuk meneliti pada populasi atau sampel tertentu, pengumpulan data menggunakan instrument penelitian, analisis data bersifat kuantitatif/statistik, dengan tujuan untuk menguji hipotesis yang telah ditetapkan”. Pada penelitian kuantitatif terdapat variabel-variabel sebagai objek penelitian.Sedangkan untuk metode penelitian yang digunakan menggunakan metode korelasional.Menurut Hasan (2002), 
metode korelasi merupakan metode yang mencari hubungan diantara variabel-variabel yang diteliti yang kemudian akan dijelaskan. Metode ini bertujuan untuk meneliti sejauh mana hubungan antara suatu variabel dengan variabel lainnya. Pada penelitian ini metode korelasi ditujukan untuk mengetahui sejauh mana hubungan kualitas web Kandaga dalam memenuhi kebutuhan informasi mahasiswa Unpad.

Populasi pada penelitian ini adalah mahasiswa aktif Universitas Padjadjaran yang terdiri dari jenjang pendidikan DIV, S1, S2, dan S3 dengan jumlah 32.900 mahasiswa.Data tersebut terhitung per tahun akademik 2018/2019.Penentuan jumlah sampel menggunakan simple random sampling sebanyak 100 responden.Pada penelitian ini menggunakan dua jenis data, yaitu data primer dan sekunder.Data primer diperoleh dari hasil kuesioner yang dibagikan kepada responden serta dari hasil wawancara.Sedangkan untuk data sekunder diperoleh dari studi kepustakaan.

Teknik pengumpulan data pada penelitian ini terdiri dari kuesioner, observasi, wawancara, dan studi kepustakaan.Kuesioner sebagai alat pengumpulan data utama untuk pengumpulan data dengan memberikan beberapa pertanyaan dari setiap indikator untuk dijawab oleh responden.Penelitian ini menggunakan skala pengukuran statistik nominal dan ordinal.Skala nominal untuk mengukur data responden dan skala ordinal untuk mengukur data penelitian.Daftar pertanyaan yang peneliti berikan kepada responden menggunakan skala Likert dengan desain jawaban sebagai berikut: $1=$ Sangat Tidak Setuju; 2 = Tidak Setuju; 3 = Netral; 4 = Setuju; 5 = Sangat Setuju.

Pada penelitian ini, teknik analisis inferensial yang dilakukan adalah uji korelasi Pearson Product Moment (r). Uji korelasi Pearson Product Moment bertujuan untuk menguji hubungan sebab akibat antara variabel X dan variabel Y. MenurutPrijana, Winoto, \& Yanto (2016),

Pearson Product Moment memiliki syarat skala pengukuran statistik yaitu menggunakan skala interval.Pada sebuah analisis korelasi Pearson Product Moment tidak disarankan untuk menggunakan skala ordinal.Namun apabila data yang ada merupakan data ordinal, maka data tersebut harus dinaikan dahulu skalanya dengan a method successive of interval.

Secara sederhana untuk mengetahui kuat atau lemahnya tingkat atau derajat keeratan hubungan antara variabel $\mathrm{X}$ dan $\mathrm{Y}$ dapat diterangkan menggunakan tabel interpretasi sebagai berikut:

TABEL INTERPRETASI KOEFISIEN KORELASI NILAI R

\begin{tabular}{|l|l|}
\hline Interval Koefisien & Tingkat Hubungan \\
\hline $0,80-1,000$ & Sangat Kuat \\
\hline $0,60-0,799$ & Kuat \\
\hline $0,40-0,599$ & Cukup Kuat \\
\hline $0,20-0,399$ & Rendah \\
\hline $0,00-0,199$ & Sangat Rendah \\
\hline
\end{tabular}

Sumber: Akdon dalam Kirom (2015) 


\section{HASIL DAN PEMBAHASAN}

\section{Hubungan Kualitas Web Kandaga Terhadap Kebutuhan Informasi Pengguna di Universitas Padjadjaran}

Berdasarkan hasil pengujian statistik menggunakan rumus Pearson Product Moment dengan derajat kepercayaan 90\%, diperoleh hasil nilai koefisien korelasi sebesar 0,731 yang menunjukkan keeratan hubungan antara kualitas web Kandaga terhadap kebutuhan informasi pengguna di Universitas Padjadjaran memiliki hubungan kuat. Hasil perhitungan $t_{\text {hitung }}(10,60) \geq t_{\text {tabel }}(1,66)$ yang artinya kualitas web Kandaga berhubungan signifikan terhadap kebutuhan informasi pengguna.

Terdapat sebuah metode untuk pengukuran kualitas website yang dinamakan WebQual.Metode ini merupakan pengembangan dari ServQual yang digunakan unuk pengukuran suatu layanan. Menurut Barnes dan Vidgen (2002) dalamEllyusman \& Hutami (2017), WebQual merupakan metode yang difungsikan untuk mengukur sejauh mana kualitas dari sebuah website. Terdiri dari 3 indikator, diantaranya Usability (Kemudahan Penggunaan), Information Quality (Kualitas Informasi), serta Service Interaction Quality (Kualitas Interaksi Layanan). Konsep yang ada di WebQual mempunyai fokus utama dengan melibatkan pengguna pada proses pengembangan serta penerapan pada layanan yang diberikan.

Saat ini kebutuhan informasi semakin meningkat seiring dengan berjalannya keragaman informasi. Menurut Guha (1978) dalamPuspitadewi, Erwina, \& Kurniasih (2016), kebutuhan informasi dapat dikategorikan menjadi 4, yaitu Kebutuhan Informasi Mutakhir (Current Need Approach), Kebutuhan Informasi Rutin (Everyday Need Approach), Kebutuhan Informasi Mendalam (Exhaustive Need Approach), dan Kebutuhan Informasi Sekilas (Catching up Need Approach).

Berdasarkan hasil wawancara dengan salah satu responden, mengatakan bahwa secara garis besar web Kandaga terhadap kebutuhan informasi pengguna dapat dikatakan baik. Hal tersebut dikarenakan web Kandaga dapat menjadi mesin pencari yang baik untuk referensi dalam mencari jurnal atau artikel yang dibutuhkan. Namun ada beberapa responden menjawab tidak setuju mengenai kualitas informasi di web Kandaga. Alasan yang diberikan responden adalah karenainformasi yang tidak lengkap.Selain itu berdasarkan hasil analisis data penelitian pada poin-poin kualitas informasi ditemukan bahwa responden lebih banyak menjawab netral, hal ini bisa terjadi karena responden kurang mengetahui tentang topik yang ditanyakan, atau bisa juga karena responden kurang menganggap bahwa kualitas informasi merupakan hal yang penting. Jadi kesimpulannya adalah secara kualitas, web Kandaga telah mampu menjadi website perpustakaan yang baik dan mampu menjadi mesin pencari informasi yang dibutuhkan oleh mahasiswa Unpad.

\begin{tabular}{|c|c|c|c|c|}
\hline Sub Variabel & $\boldsymbol{\rho}$ & $\mathbf{t}_{\text {hitung }}$ & $\mathbf{t}_{\text {tabel }}$ & Keputusan \\
\hline $\begin{array}{c}\text { Hubungan Kualitas Web Kandaga Terhadap } \\
\text { Kebutuhan Informasi Pengguna }\end{array}$ & 0,731 & 10,60 & 1,66 & $\mathrm{H}_{1}$ Diterima \\
\hline
\end{tabular}




\section{Hubungan Kualitas Web Kandaga Terhadap Kebutuhan Informasi Mutakhir bagi Pengguna di Universitas Padjadjaran}

Berdasarkan hasil pengujian statistik menggunakan rumus Pearson Product Moment dengan derajat kepercayaan 90\%, diperoleh hasil nilai koefisien korelasi sebesar 0,511 yang menunjukkan keeratan hubungan antara kualitas web Kandaga terhadap kebutuhan informasi mutakhir pengguna di Universitas Padjadjaran memiliki hubungan kuat. Hasil perhitungan $t_{\text {hitung }}(5,88) \geq t_{\text {tabel }}(1,66)$ yang artinya kualitas web Kandaga berhubungan signifikan terhadap kebutuhan informasi mutakhir bagi pengguna di Universitas Padjadjaran.

Kebutuhan informasi mutakhir yang dimaksud menurut Guha (1978) dalam Puspitadewi, Erwina, \& Kurniasih (2016), adalah informasi yang disajikan merupakan informasi dari data terbaru dan dalam kurun waktu yang relatif cepat. Selain itu pengguna terus menerus berinteraksi dengan website untuk mendapatkan informasi terbaru.Informasi terbaru dapat menjadi salah satu landasan dari pengambilan keputusan apabila informasi tersebut telah diperbarui dan disesuaikan dengan keadaan saat ini.

Secara garis besar, kualitas web Kandaga terhadap kebutuhan informasi mutakhir bagi pengguna dapat dikatakan baik.Hal ini dilihat dari hasil pengujian hipotesis yang dilakukan. MenurutFatmawati (2015), informasi yang dibutuhkan pada kebutuhan informasi mutakhir merupakan informasi secara gambaran umum mengenai informasi terbaru. Maka dari itu dapat ditarik kesimpulan bahwa pemenuhan kebutuhan informasi mutakhir bagi pengguna terpenuhi.

\begin{tabular}{|c|c|c|c|c|}
\hline Sub Variabel & $\boldsymbol{\rho}$ & $\mathbf{t}_{\text {hitung }}$ & $\mathbf{t}_{\text {tabel }}$ & Keputusan \\
\hline $\begin{array}{c}\text { Hubungan Kualitas Web Kandaga Terhadap } \\
\text { Kebutuhan Informasi Mutakhir }\end{array}$ & 0,511 & 5,88 & 1,66 & $\mathrm{H}_{1}$ Diterima \\
\hline
\end{tabular}

\section{Hubungan Kualitas Web Kandaga Terhadap Kebutuhan Informasi Rutin bagi Pengguna di Universitas Padjadjaran}

Berdasarkan hasil pengujian statistik menggunakan rumus Pearson Product Moment dengan derajat kepercayaan 90\%, diperoleh hasil nilai koefisien korelasi sebesar 0,553 yang menunjukkan keeratan hubungan antara kualitas web Kandaga terhadap kebutuhan informasi rutin pengguna di Universitas Padjadjaran memiliki hubungan kuat. Hasil perhitungan $t_{\text {hitung }}(6,57) \geq t_{\text {tabel }}(1,66)$ yang artinya kualitas web Kandaga berhubungan signifikan terhadap kebutuhan informasi rutin

Menurut Kamus Besar Bahasa Indonesia, rutin merupakan suatu kegiatan yang dilakukan teratur dan tidak berubah dalam jangka waktu panjang. Kebutuhan informasi rutin menurut Guha (1978) dalamPuspitadewi, Erwina, \& Kurniasih (2016), merupakan kebutuhan dimana sifatnya cepat dan spesifik. Pendekatan kebutuhan informasi rutin ini, menuntut adanya jawaban yang tepat dari pengolahan informasi atas apa yang dibutuhkan oleh pengguna. Pada kebutuhan ini informasi yang disajikan dalam jangka waktu panjang serta terjadwal sehingga pengguna dapat sering mengakses untuk mendapatkan informasi. 
Pada pengujian hipotesis, didapatkan hasil signifikan antara kualitas web Kandaga terhadap kebutuhan informas rutin. Secara garis besar, kualitas web Kandaga terhadap kebutuhan informasi rutin bagi pengguna dapat dikatakan baik..Hal ini terlihat dari responden banyak memberikan setuju pada pernyataan informasi yang disajikan dalam kurun jangka panjang.Artinya informasi tersebut dapat memenuhi kebutuhan informasi pengguna secara rutin dan dalam waktu yang relatif lama. Selain itu menurutFatmawati (2015), kebutuhan informasi rutin atau sehari-hari harus disajikan secara cepat dan informasi yang didalamnya merupakan informasi yang digunakan oleh pengguna seharihari. Informasi yang ada di web Kandaga merupakan informasi ilmiah yang berisi artikel, jurnal, dan berbagai macam koleksi untuk menunjang kebutuhan informasi ilmiah pengguna atau sivitas akademika Unpad. Sehingga dapat ditarik kesimpulan bahwa pemenuhan kebutuhan informasi rutin terpenuhi.

\begin{tabular}{|c|c|c|c|c|}
\hline Sub Variabel & $\boldsymbol{\rho}$ & $\mathbf{t}_{\text {hitung }}$ & $\mathbf{t}_{\text {tabel }}$ & Keputusan \\
\hline $\begin{array}{c}\text { Hubungan Kualitas Web Kandaga Terhadap } \\
\text { Kebutuhan Informasi Rutin }\end{array}$ & 0,553 & 6,57 & 1,66 & $\mathrm{H}_{1}$ Diterima \\
\hline
\end{tabular}

\section{Hubungan Kualitas Web Kandaga Terhadap Kebutuhan Informasi Mendalam bagi Pengguna di Universitas Padjadjaran}

Berdasarkan hasil pengujian statistik menggunakan rumus Pearson Product Moment dengan derajat kepercayaan 90\%, diperoleh hasil nilai koefisien korelasi sebesar 0,718 yang menunjukkan keeratan hubungan antara kualitas web Kandaga terhadap kebutuhan informasi mendalam pengguna di Universitas Padjadjaran memiliki hubungan kuat. Hasil perhitungan $t_{\text {hitung }}(10,21) \geq t_{\text {tabel }}(1,66)$ yang artinya kualitas web Kandaga berhubungan signifikan terhadap kebutuhan informasi mendalam.

Kebutuhan informasi mendalam menurut Guha (1978) dalamPuspitadewi, Erwina, \& Kurniasih (2016), adalah kebutuhan informasi sangat tinggi yang dibutuhkan oleh pengguna. Pada kebutuhan ini, pengguna memerlukan informasi yang akurat, spesifik, lengkap, dan dapat menjawab $5 \mathrm{~W}+1$ H.Pada kebutuhan ini pengguna memiliki ketergantungan yang tinggi pada informasi yang dibutuhkan.

Pada pengujian hipotesis didapatkan hasil signifikan antara kualitas web Kandaga terhadap kebutuhan informasi mendalam. Secara garis besar, kualitas web Kandaga terhadap kebutuhan informasi mendalam bagi pengguna dapat dikatakan baik. Hal tersebut dikarenakan responden pada penelitian ini menilai bahwa informasi yang disajikan di web Kandaga dapat memenuhi kebutuhan informasi mandalam, seperti informasi tersebut dapat menjawab 5W + 1H. MenurutFatmawati (2015), indikator informasi dalam kebutuhan informasi mendalam diantaranya relevan, spesifik, dan mendalam.

\begin{tabular}{|c|c|c|c|c|}
\hline Sub Variabel & $\boldsymbol{\rho}$ & $\mathbf{t}_{\text {hitung }}$ & $\mathbf{t}_{\text {tabel }}$ & Keputusan \\
\hline Hubungan Kualitas Web Kandaga Terhadap & 0,718 & 10,21 & 1,66 & $\mathrm{H}_{1}$ Diterima \\
\hline
\end{tabular}




\section{Kebutuhan Informasi Mendalam}

\section{Hubungan Kualitas Web Kandaga Terhadap Kebutuhan Informasi Sekilas bagi Pengguna di Universitas Padjadjaran}

Berdasarkan hasil pengujian statistik menggunakan rumus Pearson Product Moment dengan derajat kepercayaan 90\%, diperoleh hasil nilai koefisien korelasi sebesar 0,641 yang menunjukkan keeratan hubungan antara kualitas web Kandaga terhadap kebutuhan informasi sekilas pengguna di Universitas Padjadjaran memiliki hubungan kuat. Hasil perhitungan $t_{\text {hitung }}(8,26) \geq t_{\text {tabel }}(1,66)$ yang artinya kualitas web Kandaga berhubungan signifikan terhadap kebutuhan informasi sekilas.

Kebutuhan informasi sekilas menurut Guha dalam Puspitadewi, Erwina, \& Kurniasih (2016), merupakan kebutuhan informasi yang bersifat ringkas namun dapat memberikan gambaran mengenai apa yang dibutuhkan oleh pengguna. Pada kebutuhan ini pengguna membutuhkan informasi sekilas namun lengkap pada suatu objek yang diperlukan dan hal-hal yang sifatnya relevan.Pada kebutuhan informasi sekilas, pengguna membutuhkan informasi dalam bentuk gambaran umum serta ilustrasi yang dikemas secara ringkas dan menarik.

Pada pengujian hipotesis antara kualitas web Kandaga terhadap kebutuhan informasi sekilas didapat hasil signifikan. Secara garis besar, kualitas web Kandaga terhadap kebutuhan informasi sekilas bagi pengguna dapat dikatakan baik. Hal tersebut dikarenakan responden pada penelitian ini menilai bahwa informasi yang disajikan di web Kandaga dapat memenuhi kebutuhan informasi sekilas. Menurut Fatmawati (2015), informasi sekilas mencakup penggunaan bahasa yang baik serta menggunakan ilustrasi yang menarik, namun mampu memenuhi kebutuhan informasi secara ringkas dan sekilas. Beberapa responden menyatakan bahwa informasi yang disajikan sudah secara ringkas dan mampu memenuhi kebutuhan informasi dalam sekali penggunaan atau secara sekilas.Sehingga pemenuhan kebutuhan informasi sekilas terpenuhi.

\begin{tabular}{|c|c|c|c|c|}
\hline Sub Variabel & $\boldsymbol{\rho}$ & $\mathbf{t}_{\text {hitung }}$ & $\mathbf{t}_{\text {tabel }}$ & Keputusan \\
\hline $\begin{array}{c}\text { Hubungan Kualitas Web Kandaga Terhadap } \\
\text { Kebutuhan Informasi Sekilas }\end{array}$ & 0,641 & 8,26 & 1,66 & $\mathrm{H}_{1}$ Diterima \\
\hline
\end{tabular}

\section{PENUTUP}

Simpulan

Berdasarkan hasil penelitian yang telah peneliti lakukan dan diuraikan pada bab sebelumnya dapat ditarik kesimpulan sebagai berikut:

1. Kualitas web Kandaga memiliki hubungan yang kuat terhadap kebutuhan informasi dikalangan pengguna di Universitas Padjadjaran. Hal tersebut karena informasi yang disajikan dalam web Kandaga dapat memenuhi kebutuhan informasi khususnya di kalangan mahasiswa. Sebagai mesin pencari informasi, web Kandaga sudah menjadi referensi bagi pengguna untuk mencari informasi ilmiah. Selain itu informasi yang 
disajikan web Kandaga ringkas, jelas, dan dimengerti oleh pengguna sehingga oleh beberapa responden pemenuhan kebutuhan informasi terpenuhi.

2. Kualitas web Kandaga memiliki hubungan yang kuat terhadap kebutuhan informasi mutakhir dikalangan pengguna di Universitas Padjadjaran. Hal tersebut karena informasi yang disajikan di web Kandaga memenuhi kebutuhan informasi mutakhir bagi pengguna khususnya di kalangan mahasiswa. Informasi yang disajikan pun dapat memberikan gambaran umum mengenai informasi terbaru. Maka dari itu pemenuhan kebutuhan informasi mutakhir terpenuhi.

3. Kualitas web Kandaga memiliki hubungan yang kuat terhadap kebutuhan informasi rutin dikalangan pengguna di Universitas Padjadjaran. Hal tersebut karena informasi yang ada di web Kandaga memenuhi kebutuhan informasi rutin yang bersifat cepat dan spesifik bagi pengguna khususnya di kalangan mahasiswa. Selain itu, informasi yang disajikan merupakan informasi yang dapat digunakan untuk kepentingan sehari-hari bagi sivitas akademika. Seperti jurnal ilmiah, artikel, dan lain-lain. Oleh karena itu, pemenuhan kebutuhan informai rutin terpenuhi.

4. Kualitas web Kandaga memiliki hubungan yang kuat terhadap kebutuhan informasi mendalam dikalangan pengguna di Universitas Padjadjaran. Hal tersebut karena informasi yang disajikan web Kandaga memenuhi kebutuhan informasi mendalam bagi pengguna khususnya mahasiswa. Informasi yang disajikan di web Kandaga lengkap dan detail serta menjawab $5 \mathrm{~W}+1 \mathrm{H}$. Oleh karena itu secara keseluruhan pemenuhan kebutuhan informasi mendalam terpenuhi.

5. Kualitas web Kandaga memiliki hubungan yang kuat terhadap kebutuhan informasi sekilas dikalangan pengguna di Universitas Padjadjaran. Hal tersebut karena informasi yang disajikan web Kandaga mampu memenuhi kebutuhan informasi sekilas seperti menggunakan bahasa yang mudah dimengerti. Selain itu informasi yang disajikan web Kandaga menggunakan ilustrasi menarik sehingga pemenuhan kebutuhan informasi sekilas terpenuhi.

\section{Saran}

Adapun saran-saran dalam penelitian ini adalah sebagai berikut:

1. Agar dapat dimanfaatkan dengan baik serta memperluas wawasan mahasiswa Universitas Padjadjaran mengenai web Kandaga, akan lebih baik apabila pengelola dapat melakukan kegiatan promosi atau sosialisasi kepada mahasiswa, seperti mengadakan acara singkat di setiap Perpustakaan Fakultas atau di Grha Kandaga.

2. Agar dapat meningkatkan kualitas web, pengelola diharapkan dapat memilki staff khusus untuk menangani web Kandaga. Karena selama ini tim yang bertanggung jawab pada pengelolaan web atau bagian IT berada di pusat. 


\section{DAFTAR PUSTAKA}

Ellyusman, S., \& Hutami, R. F. (2017). Analisis Kualitas Sistem Informasi Akademik Menggunakan Metode Importance Performance Analysis ( IPA ). Jurnal Kajian Informasi \& Perpustakaan, 5(1), 49-62.

Erwina, W., \& Yanto, A. (2017). Portal Kandaga Universitas Padjadjaran Sebagai Mesin Pencari Perpustakaan-FINAL-REVISED. Universitas Padjadjaran

Fatmawati, E. (2015). Kebutuhan Informasi Dalam Teori Dan Praktek. Info Persadha.13(1), $1-12$.

Hasan, M. I. (2002). Pokok-pokok Materi Metodologi Penelitian dan Aplikasinya. Bogor.

Kirom, B. (2015). Mengukur Kinerja Pelayanan dan Kepuasan Konsumen. Bandung: Pustaka Reka Cipta.

Prijana, Winoto, Y., \& Yanto, A. (2016). Metode Penelitian Kuantitatif. Bandung: Unpad Press.

Puspitadewi, I., Erwina, W., \& Kurniasih, N. (2016). Pemanfaatan "Twitter TMCPOLDAMETRO” Dalam Memenuhi Kebutuhan Informasi Para Pengguna Jalan Raya. Jurnal Kajian Informasi \& Perpustakaan, 4(1), 21-28.

Riyadi, T. (2009). Jenis-jenis Search Engine. Diambil kembali dari Web Ilmu Komputer. Sumber:

http://www.ilmukomputer.org/wpcontent/uploads/2009/08/jenis_search_engine_taufan_riyadi.pdfDiakses 23 Mei 2018.

Sugiyono. (2012). Metode Penelitian Kombinasi (Mixed Methods).Bandung: Alfabeta.

Suprianto, W., \& Muhsin, A. (2008). Teknologi Informasi Perpustakaan. Bandung: Kansius.

Yanto, A., \& Erwina, W. (2018). Kajian Perpustakaan dan Sains Informasi Kontempore. (M. P. Prof. Dr. Heri Suwignyo, Ed.). Universitas Negeri Malang. 